\title{
FODEM: a multi-threaded research and development method for educational technology
}

\author{
Jarkko Suhonen • M. Ruth de Villiers • Erkki Sutinen
}

Published online: 20 October 2011

(c) Association for Educational Communications and Technology 2011

\begin{abstract}
Formative development method (FODEM) is a multithreaded design approach that was originated to support the design and development of various types of educational technology innovations, such as learning tools, and online study programmes. The threaded and agile structure of the approach provides flexibility to the design process. Intensive stakeholder feedback is a vital aspect of FODEM. As a formative method that emphasizes research-orientation and evaluation through the entire development process, this article proposes that FODEM is fundamentally also a research and development method. FODEM provides tools to conceptualize the development process via its distinguishing feature, namely a dynamic thread structure. FODEM can be used to manage, analyse and visualise the overall design process at different stages. FODEM can also be used to create different conceptulisations of a design process in order to identify successes and failures.
\end{abstract}

Keywords Design approach · Educational technology · Evaluation · Innovations · Research and development method

\section{Introduction}

Information and communication technology (ICT) plays an important role in current learning environments. Rapidly emerging technological solutions such as mobile devices, Web 2.0 applications and educational games, provide new possibilities to support learning.

\footnotetext{
J. Suhonen $(\bowtie) \cdot$ E. Sutinen

School of Computing, University of Eastern Finland, Joensuu Campus, PO Box 111, 8010 Joensuu, Finland e-mail: jarkko.suhonen@uef.fi

E. Sutinen

e-mail: erkki.sutinen@uef.fi

M. R. de Villiers

School of Computing, University of South Africa, Muckleneuk Campus, PO Box 392, UNISA 0003 Pretoria, South Africa

e-mail: Dvillmr@unisa.ac.za
} 
Advanced ICT solutions can also serve as agents of change-reforming, enhancing and improving educational practices.

Despite multiple efforts, educational technology has not had the anticipated impact in real learning settings (Amiel and Reeves 2008). Development of viable educational technology solutions is a complex process involving interactions between human, social, cultural and technical aspects. When novel ICT solutions are designed, the requirements and expectations for the end results are expected to change during the development process, because of the specific requirements of the settings (Fallman 2003). The design process should be able to react proactively to such changes. A design method that supports the design and development process dynamically can help designers to tackle the abovementioned challenges (Design-Based Research Collective 2003). Formative Develoment Method (FODEM) approach has been developed specifically for the contexts of sparse learning communities and situations of low financial resources following the Nordic principles of IT development, namely: demand-driven design, light management, agile implementation and formative evaluation of the design products (Hansson et al. 2009). FODEM uses parallel, synchronous and dynamic thread structures to manage and conceptualize various aspects of informed design of innovative educational technology. The approach supports both phased and non-linear development processes and can react quickly to identified challenges and requirements. In particular, these fast development cycles with their light management procedures support low-resource development. Furthermore, FODEM offers ways to manage, conceptualise and visualise the dynamic aspects of the design and development process in a practical way. Most important, FODEM highlights research and continuous multi-method evaluation as an important aspect of the design process. The approach enables designers to model and investigate the design and development process, including its successes and failures (Suhonen and Sutinen 2006).

In the present work we argue that FODEM is fundamentally an integrated research and development method. In this regard, we will compare its features to other research and development methods applied in educational technology. In addition, towards the end of the article, we will investigate features of FODEM in relation to Creswell's (2009) research design framework. The work reported in this article is based on the outcome of several years' empirical research in designing, developing, and evaluating online study programmes and learning tools. FODEM's ongoing real-world implementation in the ViSCoS context has been described (Suhonen and Sutinen 2006) and is revisited in this article, along with discussions on current FODEM implementations. Furthermore, in this work we present a new FODEM visualization scheme. The purpose of the present study is to demonstrate FODEM's similarities to other research and development methods, yet to highlight its distinguishing features.

The paper is constructed as follows. In the next section, we provide an overview of related research and development methods in educational technology, before presenting FODEM's approach and features. The third section gives examples of FODEM implementations and the associated research. Having described FODEM, we explain why FODEM is, in its own right, a research and development method as well as a design approach. Finally, we conclude the results of our work and discuss future challenges.

\section{Educational technology research and development methods}

In order to address the role of FODEM as a research and development (R\&D) method, we first discuss about three R\&D methods: action research, development research, and 
design-based research. This allows us to compare and relate the features of FODEM to other R\&D methods applied in educational technology.

R\&D methods integrate research as a vital part of the design and development of an educational technology innovation. According to Conole et al. (2004) and Amiel and Reeves (2008), R\&D methods are essential in educational technology, since they provide both practical and theoretical results. R\&D methods are applied in complex real-world settings, where researchers operate in a dual mode of research and design (Reeves 2000b). We can identify various inter-related research goals within the R\&D methods (Reeves 2000a): (1) In action goals, the focus is on particular educational technology innovations to determine their effectiveness and solve specific educational problem. (2) Within development goals, the aim to solve practical real-world problems while simultaneously constructing generalizable design principles to guide future developments. (3) In constructive goals, the focus is on creating novel solutions, models and algorithms (Glass et al. 2004).

Action research: practitioners solving an identified real-world problem

Action research (AR) involves a variety of research and intervention methods. It is characterized by a participative practitioner-researcher ethos, where practitioners solve practical problems, e.g. teachers improving their professional practices by developing technological interventions (Avison et al. 1999; Cohen et al. 2000; de Villiers 2005). AR is often used as an agent of change to solve 'how to' questions (Baskerville 1999; Germonprez and Mathieassen 2004). It is cyclic and longitudinal, as an evolving intervention is investigated and evaluated over several cycles (Baskerville and Wood-Harper 1996), leading to repetitive processes of critical reflection, response and action in each cycle, which Zuber-Skerrit (1992) terms 'plan, act, observe, and reflect'. Figure 1 shows this series of cycles providing input to each other. Action research and its findings are grounded in particular contexts, because the researcher-developer is often a direct participant.

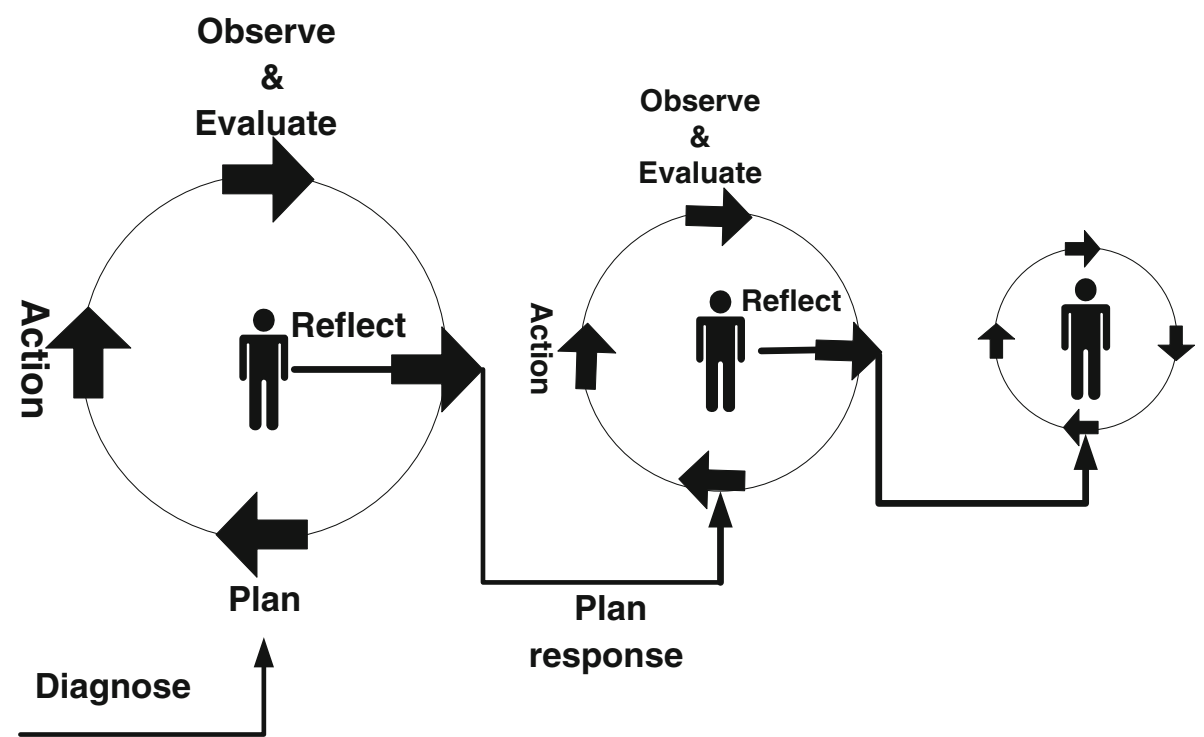

Fig. 1 Action research process (de Villiers 2005) 
Development research: deriving generalisable design principles from a concrete development process

Development research (DR) (Reeves 2000b) comprises iterative analysis, design, development, implementation, and evaluation phases. Critical reflection leads to continuous refinement of problems, solutions and research methods. DR goes beyond AR in its dual objectives of identifying practical solutions to real-world problems, while also developing generic design principles as shown in Fig. 2 (de Villiers 2005). The artifacts produced are investigated to determine how and why they work. Some situations are so new that designers apply intuition, informal experience and trial-and-error. Development research is closely related to evolutionary prototyping, an approach that is applied in contextual design of ICT.

Design-based research: producing contextually relevant theories by analyzing innovative design processes

Design research originates from design science, which focuses on investigating man-made objects and artificial phenomena in applied sciences, e.g. engineering, product design, and instructional design (Simon 1981). In education, this emerging R\&D approach is called design-based research (DBR) (Barab and Squire 2004; Design-Based Research Collective 2003; Wang and Hannafin 2005). According to Amiel and Reeves (2008), DBR aims to build a strong connection between educational technology research and complex realworld problems. DBR involves the development of innovative educational technology solutions and creation of contextual learning theories. DBR resembles development research, as it occurs through cycles of analysis, design, evaluation and redesign, at times using design experiments. It extends DR, as it particularly addresses difficult situations that require novel, even unique, solutions. In these processes, both the successes and failures should be considered and explained. When evaluation results are analysed, new design solutions are implemented, producing a design-reflection-design continuum.

Table 1 portrays the three R\&D methods, summarizing their goals, features, processes, and application areas. The main commonality is that they all view research as a constructive endeavor, tightly interwoven with parallel and synchronous design, implementation, and evaluation processes (Reeves 2000b). Moreover, all three are iterative and

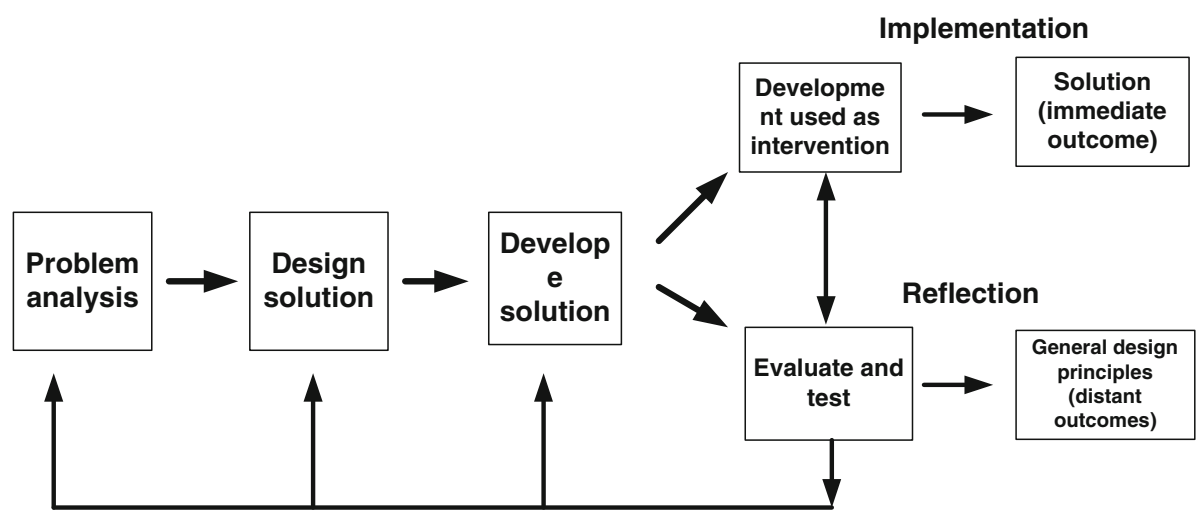

Fig. 2 Development research model (de Villiers 2005, influenced by Reeves 2000a) 
Table 1 Summary of R\&D methods in educational technology

\begin{tabular}{|c|c|c|c|}
\hline \multirow[t]{2}{*}{ Aspects } & \multicolumn{3}{|l|}{ Method } \\
\hline & Action research & Development research & Design-based research \\
\hline \multirow[t]{2}{*}{ Goals } & \multirow[t]{2}{*}{$\begin{array}{l}\text { Developing interventions to } \\
\text { solve practical problems; } \\
\text { Advancing local } \\
\text { knowledge without } \\
\text { necessarily constructing } \\
\text { generalizable theory or } \\
\text { principles }\end{array}$} & $\begin{array}{l}\text { (1) Development of } \\
\text { innovative and effective } \\
\text { solutions to real problems } \\
\text { (2) Models and transferable } \\
\text { design principles to inform } \\
\text { future work }\end{array}$ & $\begin{array}{l}\text { (1) Implementation of novel } \\
\text { educational technology } \\
\text { solutions in complex } \\
\text { situations } \\
\text { (2) Development/extension } \\
\text { of contextual learning } \\
\text { theories }\end{array}$ \\
\hline & & \multicolumn{2}{|c|}{ DR and DBR have dual foci, as shown above. } \\
\hline $\begin{array}{l}\text { Distinct } \\
\text { features }\end{array}$ & $\begin{array}{l}\text { Evolving products } \\
\text { investigated over several } \\
\text { cycles; longitudinal time } \\
\text { frame; reflective and } \\
\text { responsive to findings from } \\
\text { previous cycles; In-depth } \\
\text { involvement of researcher- } \\
\text { practitioner } \\
\text { Practical, contextual and } \\
\text { locally relevant }\end{array}$ & $\begin{array}{l}\text { Problem-oriented } \\
\text { Acknowledges complex and } \\
\text { dynamic relationship } \\
\text { between theory, principles, } \\
\text { practice and application }\end{array}$ & $\begin{array}{l}\text { Rigorous and reflective } \\
\text { inquiry into difficult real- } \\
\text { world problems in } \\
\text { education or training } \\
\text { Contextually-sensitive } \\
\text { Design experiments are } \\
\text { conducted to find both } \\
\text { practical (innovative } \\
\text { designs) and theoretical } \\
\text { outputs (contextualized } \\
\text { learning theories) }\end{array}$ \\
\hline \multirow[t]{2}{*}{ Processes } & $\begin{array}{l}\text { Cyclical phases: plan, act, } \\
\text { observe and reflect } \\
\text { Participative: collaboration } \\
\text { between researcher, } \\
\text { practitioner, and end-user } \\
\text { Emancipatory: AR as a } \\
\text { change agent }\end{array}$ & $\begin{array}{l}\text { Iterative analysis, design, } \\
\text { development, } \\
\text { implementation and } \\
\text { evaluation processes } \\
\text { Problems clarified and } \\
\text { solutions refined during the } \\
\text { design process of an } \\
\text { innovation. }\end{array}$ & $\begin{array}{l}\text { Continuous cycles of } \\
\text { analysis, design, } \\
\text { development, enactment, } \\
\text { and redesign } \\
\text { Usually conducted in multi- } \\
\text { disciplinary teams } \\
\text { Uses hybrid research } \\
\text { techniques and multiple } \\
\text { data sources }\end{array}$ \\
\hline & \multicolumn{3}{|c|}{ All three have iterative/cyclic design processes } \\
\hline $\begin{array}{l}\text { Application } \\
\text { and } \\
\text { examples }\end{array}$ & $\begin{array}{l}\text { Development of new } \\
\text { educational technology } \\
\text { materials/products to } \\
\text { reform teaching or } \\
\text { improve institutional } \\
\text { practices }\end{array}$ & $\begin{array}{l}\text { Design team produces an } \\
\text { educational technology. } \\
\text { Innovation through } \\
\text { iterative prototyping } \\
\text { Simultaneously the team } \\
\text { investigates and creates } \\
\text { design models and } \\
\text { principles to inform future } \\
\text { development in wider } \\
\text { contexts }\end{array}$ & $\begin{array}{l}\text { Educational researchers } \\
\text { develop a novel learning } \\
\text { environment to solve } \\
\text { practical problems in an } \\
\text { educational institution with } \\
\text { distinctive challenges } \\
\text { While they design, } \\
\text { implement and evaluate } \\
\text { the environment, the team } \\
\text { also refines contextual } \\
\text { theories and models } \\
\text { regarding the use of ICT to } \\
\text { support teaching processes } \\
\text { and learning activities }\end{array}$ \\
\hline
\end{tabular}

reflective in nature. However, there are differences as portrayed in Table 1. AR emphasises a specific programme, product or practice, longitudinally investigating, intervening, and improving it. Solutions may incidentally be transferable elsewhere, but that is not the main aim. In development research, the goal goes beyond the immediate outcome of developing new artifacts in real-word situations, aiming also to generate generic design principles to be shared with researchers and practitioners. In design-based research, novel technological 
applications are designed particularly for complex and distinctive educational situations, with a further focus on establishing and validating contextual learning theories.

\section{FODEM-formative development method}

FODEM originated from the design and development of an online Computer Science study programme, ViSCoS (Virtual Studies of Computer Science). The FODEM approach was created to address the following design challenges in the ViSCoS context:

- Financial and human resources were limited;

- Development periods needed to be short and they should have produced rapid results;

- The aim was to develop effective and sustainable solutions, avoiding designs based on intuition and 'recipes' (Lowyck 2002);

- The developed solutions should have been contextual, addressing local problems and supporting learners' needs (Abdelraheem 2003); and

- Design processes should be flexible and adaptable to handle unfamiliar situations and to cope with uncertainty (Moonen 2002).

\section{Components of FODEM}

The FODEM approach is based on the acknowledgement that different aspects of ICT development projects include independent and interrelated analysis, design, implementation, and evaluation components. In Fig. 3, we identify three aspects related to general ICT development projects, namely: system components of the solution; features and



Fig. 3 Modelling parallel aspects of general IT development 
functionalities; and stakeholders involved in the design process. Educational technology solutions are becoming increasingly complex to manage, so it can be very difficult to manage an entire development process via the usual software development models. As an example, consider the analysis component. From the stakeholders' perspective, analysis involves identifying the users and their specific design requirements; while from the perspective of system components, analysis could include a study of the feasibility of using existing ICT solutions in the design context (i.e. the issue of re-usability). Finally, for features/functionalities of the product, the analysis component means identifying appropriate technologies for implementing the design solutions.

In FODEM, the design and development process is conceptualized by using parallel and asynchronous development threads with a specific development theme to align the goals of the design process (Figs. 4, 5). A thread has three interdependent, dialectic components, namely: strength and needs analysis (SNA), implementation (I), and formative evaluation (FE), and can include several instances of such components (Suhonen and Sutinen 2006). Within a thread structure, SNA, I and FE components interact continuously. A thread can be, for instance, a feature of an educational application, a course in a study programme, or a system component (e.g. interface).

The strength and needs analysis component aims to identify the design constructs and concepts within a thread (Kerne 2002). The focus is on a demand-driven approach, based on the requirements of various stakeholders in their specific contexts. SNA includes the definition of the main concepts, roles and desired goals of the designed artifact from the perspective of that particular thread. An important aspect of SNA is participatory design, integrating and including end-users in the development process via techniques such as working groups, intensive workshops, and participant observations (Beyer and Holtzblatt 1997; Muller and Kuhn 1993).

The implementation component is used to develop and implement design constructs based on the identified design concepts in the SNA component. Agile approaches are emphasized when creating the design constructs: the first pilot, working prototypes or early implementations of the designs should be ready fast, enabling early experiments with users (Bahn and Naumann 1997; Quintana et al. 2002). Scenarios, mock-ups, simulations, and cooperative prototyping can be used to collect constructive feedback from learners. Observations conducted on the design constructs provide feedback that enables quick modification of the design product. The design construct must be developed at least to a level of maturity where its core functionalities are operating satisfactorily. If users are involved too late to the development process, major changes to the core functionality are costly and complex.

The formative evaluation component integrates research activities into the development process within the thread. It focuses on testing viability of the design concepts and ideas, and on identifying unsuccessful design solutions. The design constructs are evaluated via pluralistic research methods and multiple data sources, preferably in natural settings. Continuous FE, with its capacity to sustain long-term research, generates multidimensional data to support the design process. Some of the following evaluation methods can be applied: questionnaires and interviews; direct observations of end-users; and content analysis. A thread commonly includes several formative evaluation components in order to provide extensive data for future development. Input and constructive feedback from representative end-users are essential for identifying the viable design features early on and to inform subsequent development (Norman 2002). Table 2 summarises the tasks, methods, outcomes and challenges of the three FODEM components. 
Table 2 Summary of FODEM components

\begin{tabular}{|c|c|c|c|}
\hline \multirow[t]{2}{*}{ Aspects } & \multicolumn{3}{|l|}{ Components } \\
\hline & Strengths and needs analysis & Implementation & Formative evaluation \\
\hline Tasks & $\begin{array}{l}\text { Identify design solutions and } \\
\text { main concepts (Kerne } \\
\text { 2002) } \\
\text { Integrate and involve users in } \\
\text { the design process }\end{array}$ & $\begin{array}{l}\text { Implement design solutions } \\
\text { rapidly to enable early } \\
\text { experiments with users } \\
\text { (Quintana et al. 2002) }\end{array}$ & $\begin{array}{l}\text { Evaluate the design construct } \\
\text { in real-life settings in order } \\
\text { to identify viable features } \\
\text { (Norman 2002) } \\
\text { Reflect on findings and } \\
\text { provide input to components } \\
\text { within the thread or to other } \\
\text { threads }\end{array}$ \\
\hline Methods & $\begin{array}{l}\text { Analysis of contextual } \\
\text { factors (e.g. strengths and } \\
\text { needs of stakeholders and } \\
\text { design settings), learning } \\
\text { theories, and practical } \\
\text { experiences. Evaluation of } \\
\text { experiences from other } \\
\text { threads } \\
\text { Participatory design }\end{array}$ & $\begin{array}{l}\text { Rapid prototyping with } \\
\text { experimentation, agile } \\
\text { design principles (Bahn } \\
\text { and Naumann 1997) }\end{array}$ & $\begin{array}{l}\text { Pluralistic research methods } \\
\text { and multiple research data: } \\
\text { questionnaires, interviews, } \\
\text { logfiles, descriptive textual } \\
\text { data }\end{array}$ \\
\hline Outcomes & $\begin{array}{l}\text { Pedagogical and technical } \\
\text { design principles and } \\
\text { solutions within a thread }\end{array}$ & $\begin{array}{l}\text { Design constructs that can } \\
\text { be tested and evaluated in } \\
\text { authentic learning settings }\end{array}$ & $\begin{array}{l}\text { Data and experiences from } \\
\text { real-world use of the design } \\
\text { construct are used to guide } \\
\text { future developments }\end{array}$ \\
\hline Challenges & $\begin{array}{l}\text { Incorporation of design ideas } \\
\text { from different origins in a } \\
\text { meaningful way } \\
\text { (Abdelraheem 2003) }\end{array}$ & $\begin{array}{l}\text { Exposing products to users } \\
\text { prematurely or too late } \\
\text { Creating experiments that } \\
\text { produce constructive } \\
\text { feedback }\end{array}$ & $\begin{array}{l}\text { Obtaining constructive, } \\
\text { relevant and useful feedback } \\
\text { beyond the immediate } \\
\text { features and functionalities } \\
\text { of the design construct } \\
\text { (Kommers 2004) }\end{array}$ \\
\hline
\end{tabular}

Figure 4 provides a visual representation of the FODEM thread structure with several components. Each FODEM representation is a snapshot of a certain point of time in a development process. The size of the component circle indicates its importance to the thread. Large circles represent components of great importance to the development at particular moments (e.g. critical and high priority), while small circles depict components with low priorities. The colors represent the activity levels of the components:

- Red: highly active component; tasks in the component are done frequently;

- Yellow: moderately active component;

- Green: component currently in a break (inactive), but can be reactivated.

- Blue: dormant component, where no activities occurred over a considerable period of time. The possibility of reactivation exists, but obsolescence is more likely; and

- White: the component has become obsolete; no activities over an extensive period of time.

The size of a circle and its color present a double message; e.g. a small blue circle means that the component is no longer relevant from the perspective of the thread and is likely to become an obsolete component. On the other hand, a large red circle indicates that the component is currently critical and carries a heavy work load. On an intermediate level, 


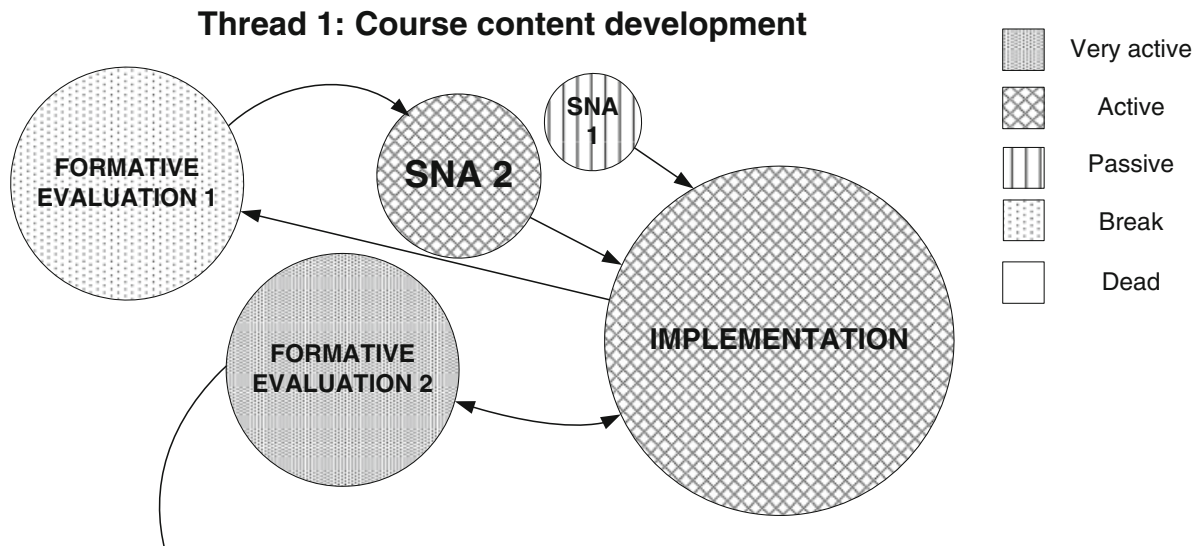

Thread 2: Interactive visualisations

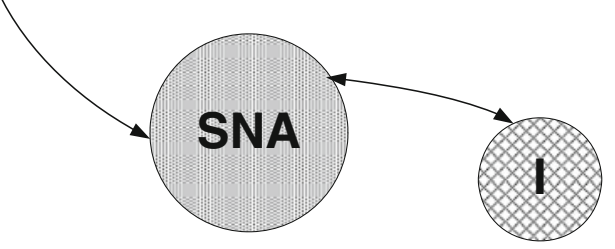

Fig. 4 An example of FODEM scenario

a large green component indicates that the component is viewed as important to the development, but that there has been a period of cessation of concrete activities. When all the components degrade to small white circles, the whole thread becomes obsolete. Since this article is not printed in color, the importance aspect of the component is presented using different background patterns in the following figures.

Dependencies and thread structures

Under FODEM, dependencies are used to represent the interdependent structure of threads and interactions between components in different threads. Thread dependencies show relationships between two independent threads (see Fig. 4 for an example). Component dependencies are depicted by directed arrows representing interaction between two components-one-directional or bi-directional, the latter representing mutual dependencies. The name of a dependency indicates the nature and meaning of the interaction.

When a development process is extensive, a thread can be divided into a set of subthreads. In this case, a triangle can be used (as in Fig. 6) to present a design view in a higher level of abstraction. In multi-layered threads, dependencies exist between thread layers and sister sub-threads. However, a thread needs a clearly identifiable theme and must include at least one component instantiation. The thread structure often changes, depending on the dynamics of the design and development process. For example, during real-world development, some original threads may fade away, while new threads emerge during the course of the development. 
Steps in the application of FODEM, followed by an illustration

The following steps can be used in applying FODEM:

(1) Identify the main aspects of the design context and settings for the initial thread structure. One tool that can be applied in this step is a concept mapping tool.

(2) Prioritize the identified threads in order to focus on the most important aspects of the design process.

(3) Start working with the SNA components in those threads that are viewed as the most important.

(4) Add new components, sub-threads and threads as the development evolves.

(5) If necessary, create a new representation of the design process.

\section{Illustration}

A design team in a higher-education institution uses the FODEM approach at the commencement of the design and development process of a community learning environment. FODEM's thread structure is used to identify the most critical aspects of the design process. From the early stages, extensive feedback is collected from students and teachers to obtain their opinions on the various prototypes generated. There is also a strong research orientation, as the developer-researchers critically evaluate the process and progression. The team regularly uses FODEM to model and analyse the design and development, in order to get a picture of the dynamic and adaptive process.

After working with the environment for a few years, the team uses FODEM to model the current situation. They discover notable successes, but also note that some of the original ideas had not materialized due to financial restrictions, and that some of the implemented features had been unsuccessful and discontinued.

\section{Examples of FODEM in action}

In this section, we show how FODEM was used to conceptualise the design and development processes of the ViSCoS online study programme. We also show how FODEM is applied in capturing the most important development aspects of the IMPDET online study programme. Moreover, we explain how FODEM is used to create two different representations of the same ViSCoS R\&D process in Figs. 5 and 7.

Virtual studies of computer science

FODEM initially emerged as a result of the design and development process of the Virtual Studies of Computer Science (ViSCoS) online study programme for first year (university level) Computer Science studies. The programme targeted high school students in sparsely populated region of North-Karelia in Finland, and originally comprised seven online courses (Torvinen 2004; Suhonen and Sutinen 2007). Figure 5 shows how FODEM was used to conceptualize the ViSCoS R\&D design process in Fall 2010, using the triangle scheme. Five main development threads were identified: ViSCoS Basic Studies, Online Learning Tools, English Version of Basic Studies, ViSCoS Mobile and ViSCoS Intermediate Studies. Figure 5's triangular notation presents a general overview of the design process indicating that all five threads comprise one or more sub-threads. 


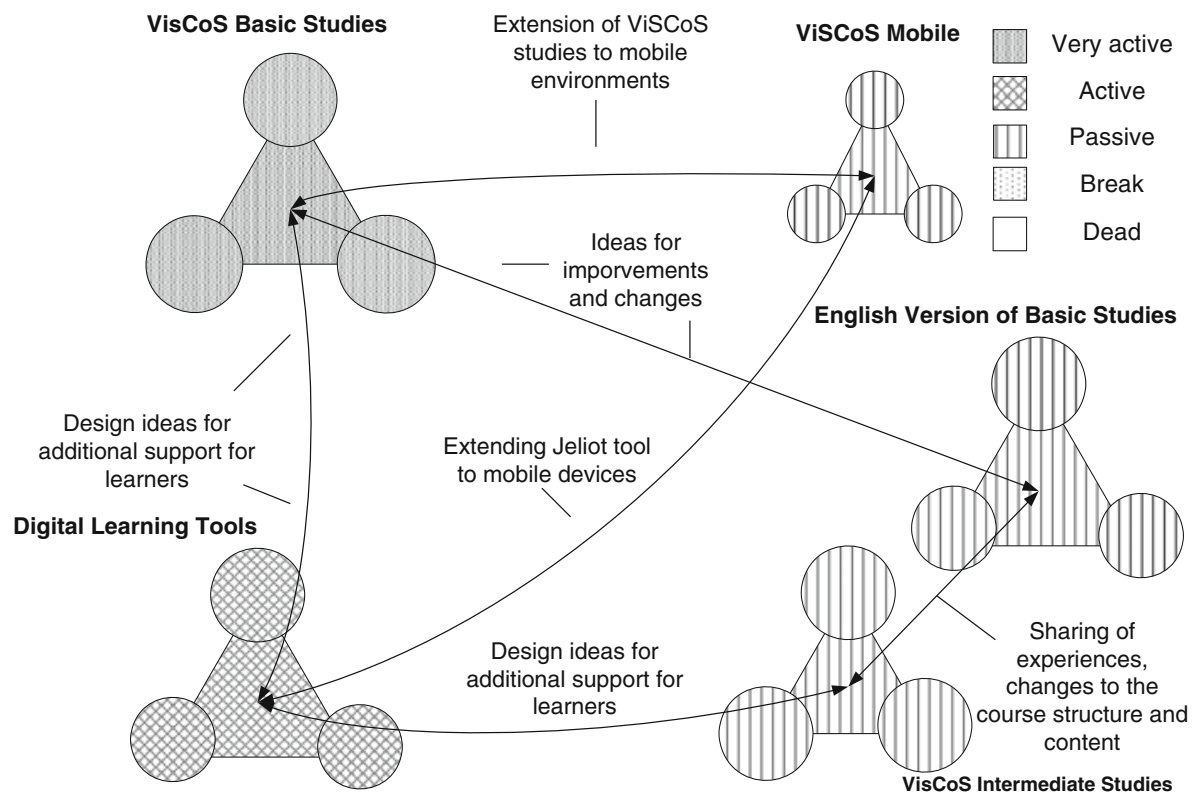

Fig. 5 FODEM conceptualization of the general ViSCoS design and development process

The ViSCoS Basic Studies thread represents the core development in the design process of ViSCoS. A specific aspect of ViSCoS studies has been the development and integration of online learning tools. Within the Online Learning Tools thread, the following scaffolding tools have been developed or integrated as part of the ViSCoS studies:

(1) LEAP: LEArning Process companion to support students' work in the programming project course (Suhonen and Sutinen 2004)

(2) Jeliot: an environment by which learners can visualize Java code (Moreno et al. 2004).

(3) An automated assessment tool in Moodle. The purpose of introducing automatic assessment solutions is to decrease the workload of instructors, enabling them to focus more on support activities than on laborious manual assessment.

The English Version thread materialized when ViSCoS courses were implemented in the English language and run in 2005-2006. ViSCoS Mobile thread focuses on developing mobile learning solutions (Laine et al. 2006). Two prototypical applications have been developed in the ViSCoS Mobile thread: a mobile blog environment and a tool for compiling and running Java programs via a mobile phone (Laine and Suhonen 2008). Finally, development of the ViSCoS Intermediate Studies commenced in 2008 with the goal of extending the study programme to include additional studies.

In Fig. 6, we zoom into the ViSCoS Basic Studies thread to show details, some of which are addressed in the ensuing discussion. The identified sub-threads are: First Designs, Loop of Improvements, Structural Curriculum Development and Automatic Assessment of Exercises.

In the First Designs sub-thread of ViSCoS Basic Studies thread, the initial ViSCoS courses were implemented in 2000 and 2001. Intensive research accompanied the first 


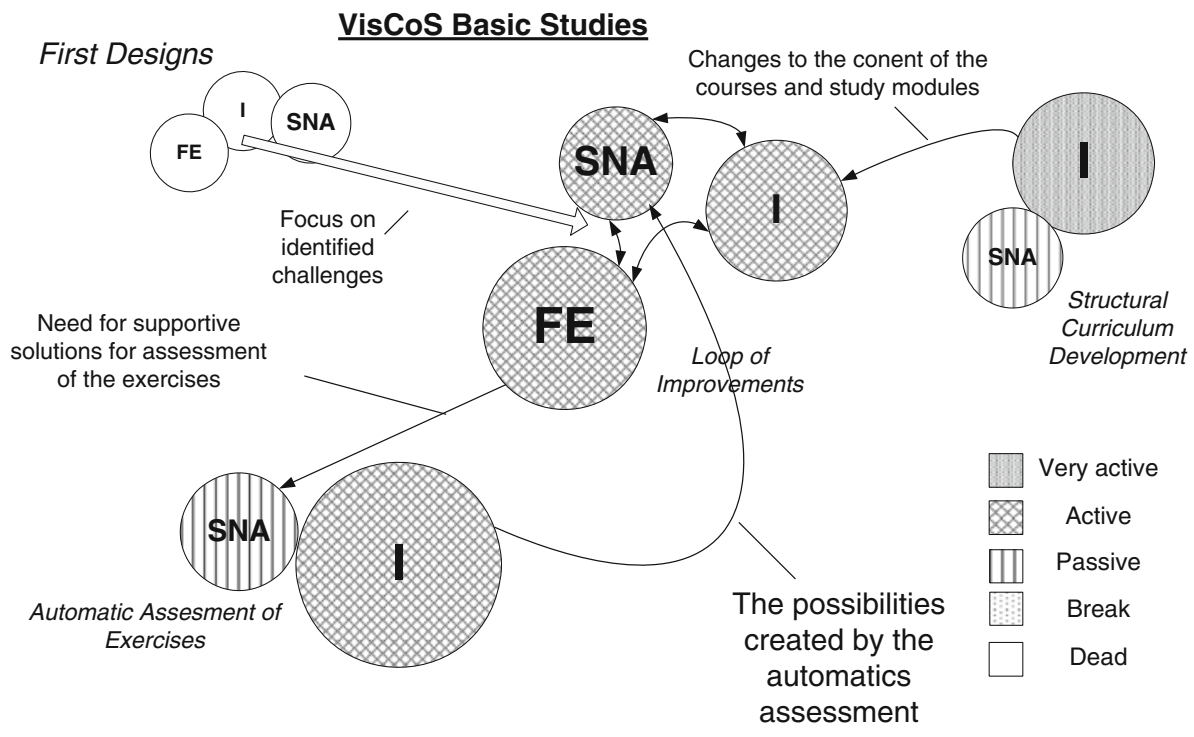

Fig. 6 Zoom into the ViSCoS basic studies thread

implementations, as feedback was collected from the learners, identifying reasons for the difficulties (Meisalo et al. 2003). The main challenge in the ViSCoS studies, from the very beginning, was the dropout phenomenon. The evaluations carried out with students indicated that that programming courses were the most difficult for students (Meisalo et al. 2004). The main reasons for the attrition were lack of time, difficult exercises and failure in examinations. Many students found it difficult to study independently. They required more support on complex programming topics, such as arrays, methods, applets, and animations (Meisalo et al. 2003).

The Loop of Improvements thread responded to problems identified in the first designs thread (Torvinen 2004). The content and structure of ViSCoS Basic Studies have evolved iteratively within the loop of improvement thread according to requirements and emerging needs. The refinement of ViSCoS courses between 2002 and 2004 resulted from extensive evaluation of the courses and their content, learning environments, and general arrangements of the studies. Research was conducted to investigate the attrition issue by using mix of data sources, such as questionnaires, interviews log files, analysis of examination papers and scripts; submitted exercises; and analysis of student and tutor feedback (Meisalo et al. 2004; Torvinen 2004). For instance, questionnaires were used to investigate the most challenging aspects of the studies. In addition, interviews generated in-depth information about learners' opinions regarding the challenges in their studies, study processes and learning techniques; as well as attitudes and motivation towards studies.

During 2004-2009, the Loop of Improvements thread was not as active as in the early years of ViSCoS development. However, continuous minor changes have been implemented to course structures, course content, learning materials, and student support services. Two threads emerged in year 2010: Automatic Assessment of Programming Assignments and Structural Curriculum Development, where the focus is on automatic assessment for programming courses and modification of the structure of the ViSCoS studies.

Figure 7 presents another FODEM representation of the ViSCoS Basic Studies thread. In this conceptualization, individual ViSCoS courses in the basic level and online learning 


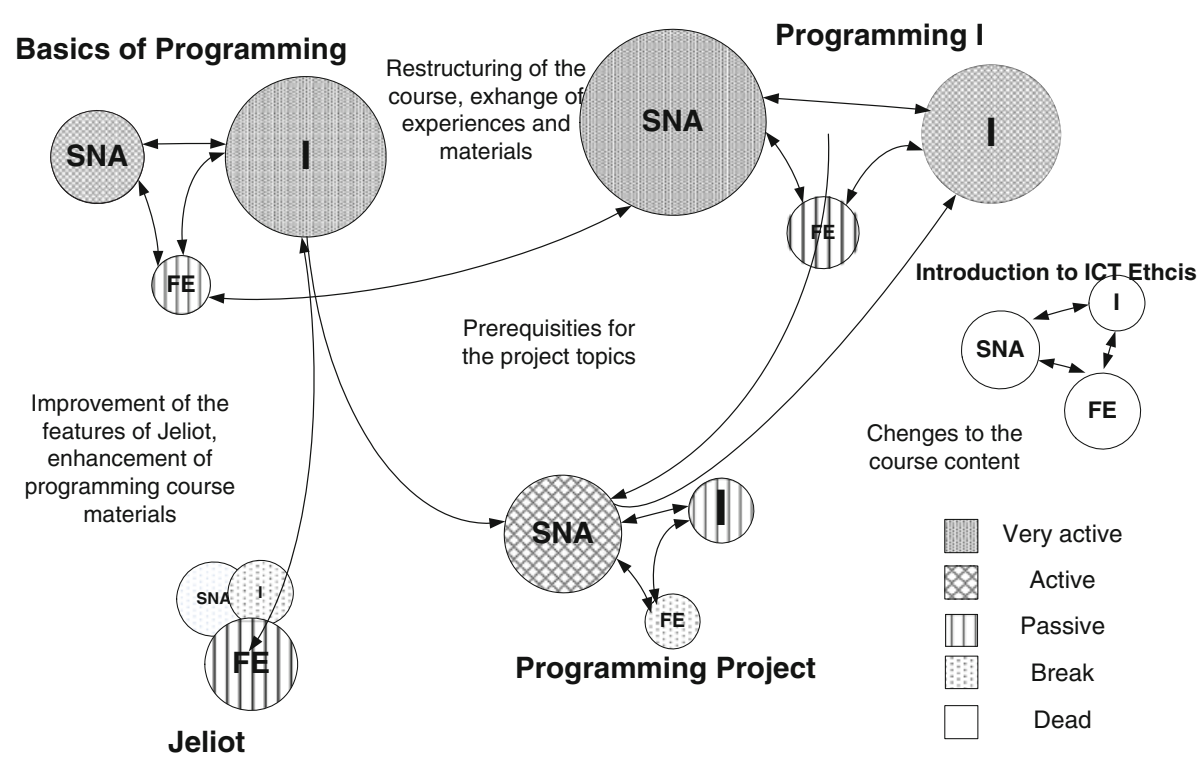

Fig. 7 Another perspective on the ViSCoS basic studies thread

tools applied in the ViSCoS studies are depicted as threads. Figure 7 shows, for instance, that the thread, Introduction to ICT Ethics, has become obsolete, the course having been removed from the ViSCoS curriculum in 2008.

IMPDET online study programme

International Multidisciplinary PhD Studies in Educational Technology (IMPDET) is an online programme whereby students study towards a PhD degree in Computer Science or Education, specializing in educational technology. The planning and design of IMPDET commenced in 2004 and the first students enrolled in 2005. By late 2010, around 30 students from 12 different countries have been undertaking IMPDET studies. In Fig. 8, a concept map representation is used to identify the main aspects of the IMPDET's development process in Fall 2010, namely, Doctoral Studies Coursework, Interdisciplinary Collaboration, Expert Network, and Online Mentoring and Student Support. The concept map is then transformed into FODEM representation in Fig. 9 including the main threads.

In 2010, the main focus was on re-structuring the doctoral studies coursework and developing novel solutions for online supervision and community building, as shown in Fig. 9. The other threads slightly faded away at that particular time of the development.

Next we will discuss about the two active threads in 2010, namely Doctoral Studies Coursework and Online Mentoring and Student Support. In the Doctoral Studies Coursework thread, the focus is on the development of postgraduate studies (e.g. coursework) within the IMPDET programme. The three sub-threads identified in the thread are: Online Courses, PhD Days and Forest Camps. In the Online Courses sub-thread, the emphasis has been on development of IMPDET courses. International educational technology experts were originally employed to create ten online courses. By 2008 and 2009, it was necessary to change the structure, since it was no longer possible to maintain and teach 


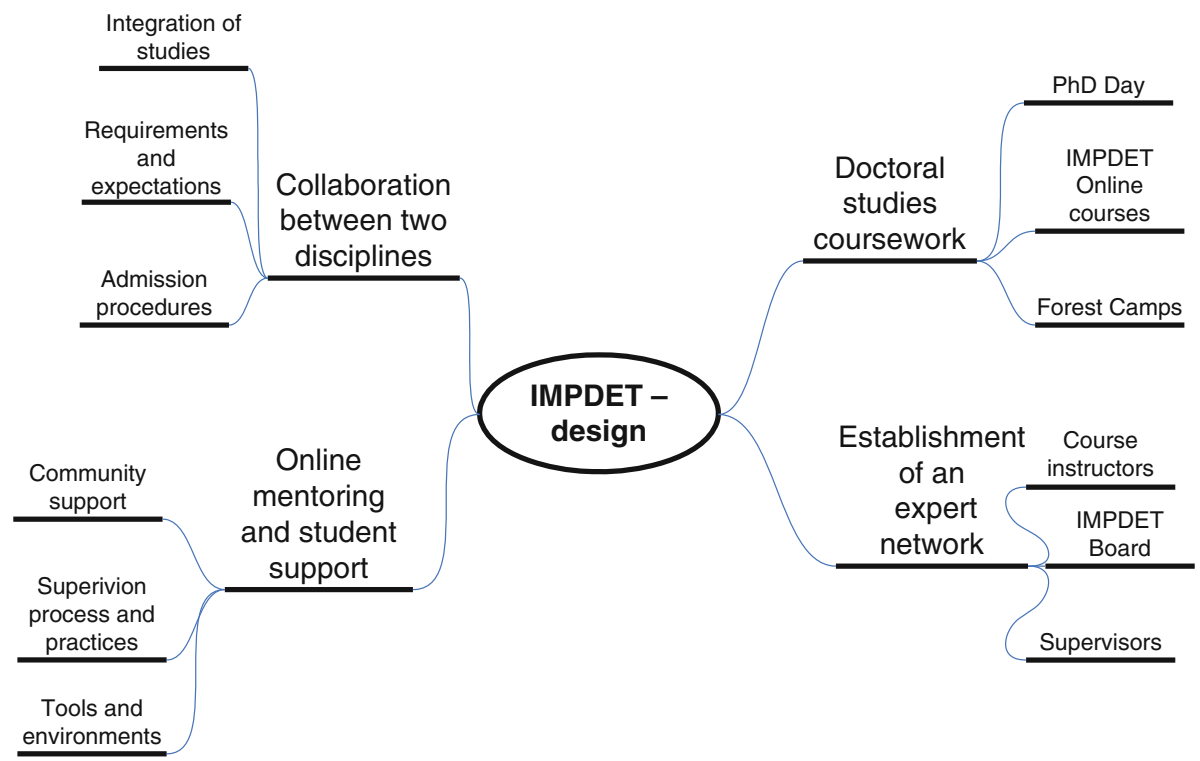

Fig. 8 Concept map of the main design aspects of IMPDET

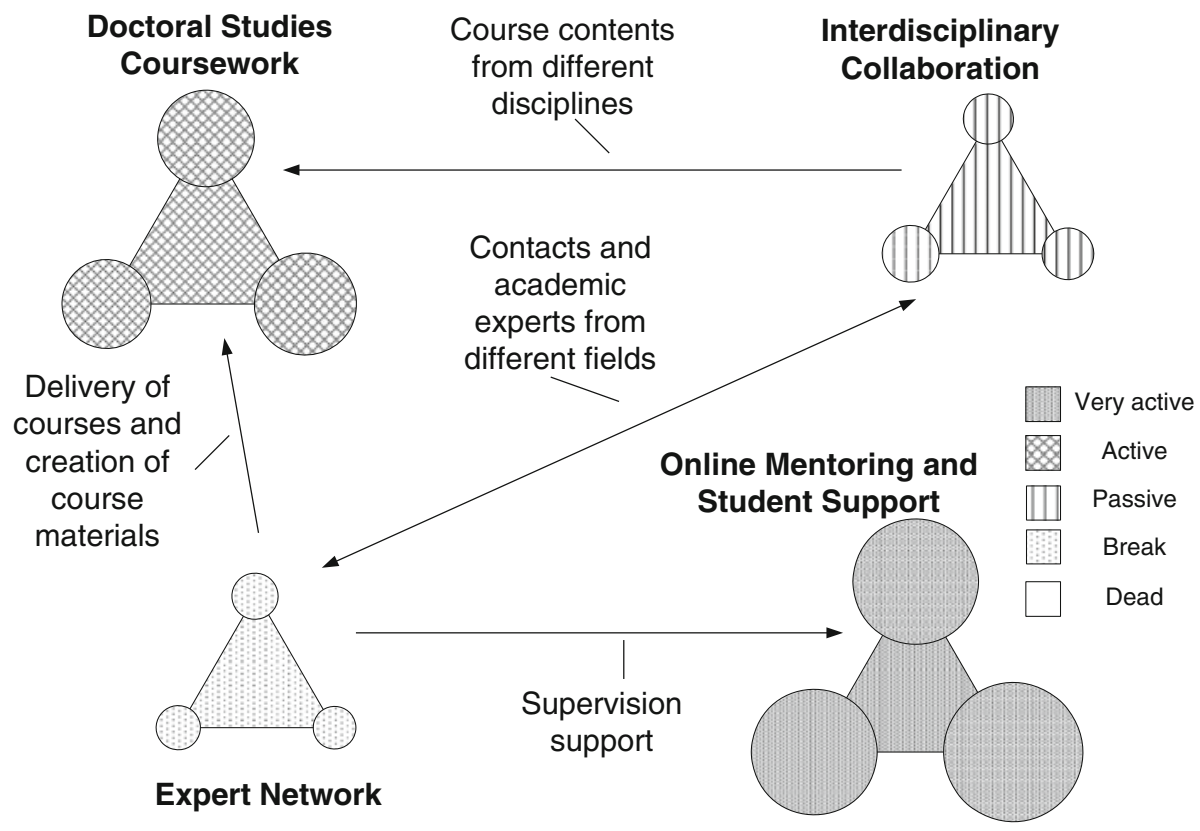

Fig. 9 FODEM conceptualization of the IMPDET programme in 2010

the ten original IMPDET courses. For instance, individual learning tasks related to doctoral studies were introduced, such as literature reviews, research seminars, and practicum in online learning. 
The goal of the PhD Day sub-thread is the development of research seminars, where students present and discuss their $\mathrm{PhD}$ work and progress. Initially, only local students participated, but recent technological ventures have supported participation by global learners. Skype conference calls have been used and, more recently, Adobe Connect Pro has been successfully employed to support distance learners in participating and contributing to the PhD Day. The Forest Camp sub-thread aims to offer contact tutoring and learning for IMPDET students. From 2004 to 2007, 'Forest Camps' were held, where students were instructed and supervised face-to-face by educational technology experts. For financial reasons, these contact events were not held after 2007, thus the thread has become dormant.

An important main thread in 2009 and 2010 was the search for new solutions to supervision and community support, realised via the Mentoring and Student Support thread (Paliktzoglou et al. 2010). One of the sub-threads of this particular thread has been an investigation of the use of Web2.0 tools in the IMPDET programme. For example, preliminary experiments have been undertaken with Mahara e-learning portfolio and a Wiki platform in order to support the community building and supervision aspects of the studies.

\section{FODEM as an educational technology $R \& D$ method}

In this paper we (1) introduced the FODEM design approach and (2) provided concrete examples of how it has been used to represent different educational technology design and development processes. The questions arise: Is FODEM more than instructional design? Is FODEM indeed a research and development method? To address this, we first re-visit Table 1, and its first three row headers to analyse FODEM as a R\&D approach. Thereafter, we categorize FODEM according to Creswell's (2009) Framework for Design.

\section{Goals}

The FODEM approach supports gradual, open-ended development and responsive problem solving, based on the strengths and needs of respective stakeholders. FODEM's component and thread structure provides tools and notations to manage synchronous, interdependent and dynamic development aspects.

\section{Distinctive features}

The method provides tools to prioritize various aspects of the design process. Multiple data collection methods are used to inform the contextual design and development of the design constructs. The thread structure can be used to manage multiple perspectives such as the technical, educational and administrative aspects. FODEM also provides tools to plan and present various design alternatives. By means of these, the dynamic aspects of a development process can be managed. Alternative representations and conceptualizations of a same development process can be created, such as shown in Figs. 5 and 7. Furthermore, the method can also be used to generate constructive research output by retrospective conceptualization and analysis of educational technology development paths.

\section{Processes}

FODEM has a parallel and dynamic thread structure, with diverse foci, tasks and time spans. Development can be iterative as in other R\&D methods, but also supports phased 
development. The design process is based on asynchronous threads; a thread can be active, passive, obsolete or fade away completely. The approach follows agile design principles with a focus on fast prototyping and end-user involvement to support contextual design and formative evaluation in its ongoing research orientation. In a rich, open and flexible way, educational features in the form of threads, are added, changed, or declared dormant, yet whatever their status, they can remain in the FODEM representation.

FODEM and the Creswell research design framework

Here we take the analysis of FODEM further by investigating whether FODEM is a full 'research design' method in line with Creswell's (2009) Framework for Design with its interconnected components. According to Creswell (2009, p. 5), research design '...involves the intersection of philosophy, strategies of inquiry, and specific methods', with the components:

1. Basic philosophical assumptions/worldviews that researchers bring to a study;

2. Overall strategies of inquiry used in the research; and

3. Actual research methods employed to operationalize those strategies.

We apply this broad framework and determine whether explicit decisions regarding all three components are evident in the approach of FODEM. Creswell's philosophical component relates to researchers' views on the nature of research, epitomized by worldviews of postpositivism; constructivism; advocacy/participatory; or pragmatism. In this regard, FODEM is characterized by a combination of an advocacy/participatory worldview due to major stakeholder involvement in participatory design and evaluation, and a pragmatic worldview in its emphasis on situations and consequences and on contextualized solutions 'that work' (Creswell 2009, p. 10). Second, Creswell's strategies of inquiry, also called research methodologies, involve quantitative research such as experiments or surveys; qualitative approaches such as ethnography, grounded theory, and case studies; or mixed methods that combine methodologies or triangulate sources. For this component, FODEM can be classified under mixed-methods, as it uses techniques ranging across the spectrum from the highly quantitative (e.g. measurable data) to qualitative studies that interpret the meanings of opinions and descriptive text from authentic situations. The third component in Creswell's framework involves the specific methods used for data collection and analysis, for example: questionnaires, performance data, observations, document studies, statistical analysis, etc. Here, FODEM uses a variety of data collection, analysis, and interpretation methods to acquire data and evaluate artifacts: mainly interviews, content analysis, questionnaires and $\log$ files. The research orientation provides openness and flexibility for experimentation, as different solutions to the emerging problems are explored. Research activities are also used to identify strengths and weaknesses within the design context and to critically evaluate the products implemented in real-world learning settings.

The preceding discussion indicates that all the components of Creswell's Framework are addressed within FODEM. For FODEM threads, explicit and considered decisions are taken that relate to each of the three components and are implemented contextually in ways appropriate to that thread. When assessed against the Framework, FODEM complies as a research design. Furthermore, due to its role in the design and development of educational technology artifacts, plus its continuous data corroboration via formative evaluation, we argue that it qualifies as a research and development method. 


\section{Conclusion and discussion}

This paper claims that FODEM is a research and development method to support design and development processes of educational technology innovations. Its research and reflection orientation throughout the lifespan of a technological solution, make FODEM a research and development method as well as a design approach. FODEM complies with Creswell's (2009) Framework for Design in that its conceptualizations take cognizance of all three of Crewell's interrelated components. FODEM has similarities to well-known R\&D methods-such as action research, development research and design-based research-used in educational technology, yet has its own distinguishing features.

FODEM is characterized by a simultaneous interdependent thread structure. The R\&D processes are conceptualized by components and by dependencies, which portray the thread structure and the interactions and dependencies between components. The incorporated tools capture the dynamics of contextualized, situated development processes. All processes are accompanied by multi-method evaluation. As a specification-oriented method, FODEM can be used to develop generic software beyond educational applications. Within educational technology, it can be used to design various types of solutions, such as digital learning environments, learning objects, visualization tools, online courses and study programmes. When novel ICT solutions are designed for education, such as artifacts and programmes for communities with limited resources, the requirements and expectations tend to change during development (Fallman 2003). FODEM's flexibility can handle this. It is not the intention to suggest that FODEM yields a better design outcome than other models or that FODEM is a superior R\&D approach. Rather, the aim is to show the value and relevance of FODEM's features in particular contexts.

Future research will apply FODEM as an impact-oriented $R \& D$ approach, aiming for proactive development and mapping of alternative solution paths. FODEM threads can be used to represent trees of potential future scenarios and analyse the possibilities and impacts of alternatives. This could support designers in generating educational technology innovations based on possible future perspectives, rather than projecting design from the present to the future. FODEM thus holds potential to become an even more powerful method for creating effective and sustainable educational technology innovations.

\section{References}

Abdelraheem, A. Y. (2003). Computerized learning environments: Problems, design challenges and future promises. The Journal of Interactive Online Learning, 2(2), 1-9.

Amiel, T., \& Reeves, T. C. (2008). Design-based research and educational technology: Rethinking technology and the research agenda. Educational Technology \& Society, 11(4), 29-40.

Avison, D., Lau, F., Myers, M., \& Nielsen, P. A. (1999). Action research. Communications of the ACM, 42(1), 94-97.

Bahn, D. L., \& Naumann, J. D. (1997). Evolution versus construction: Distinguishing user review of software prototypes from conventional review of software specifications. In F. Niederman (Ed.), Proceedings of the ACM conference on computer personnel research (pp. 240-245). New York: ACM Press.

Barab, S., \& Squire, K. (2004). Design-based research: Putting a stake in the ground. The Journal of the Learning Sciences, 13(1), 1-14.

Baskerville, R. L. (1999). Investigating information systems with action research. Communications of the Association for Information Systems, 2, Article 19. Retrieved 11 October 2011 from http://aisel. aisnet.org/cais/vol2/iss1/19. 
Baskerville, R. L., \& Wood-Harper, A. T. (1996). A critical perspective on action research as a method for information systems research. Journal of Information Technology, 11(1), 235-246.

Beyer, H., \& Holtzblatt, K. (1997). Contextual design: Defining customer-centered systems. San Francisco: Morgan Kaufmann Publishers, Inc.

Cohen, L., Manion, L., \& Morrison, K. (2000). Research methods in education (5th ed.). London: RoutledgeFalmer.

Conole, G., Oliver, M., Istroff, K., \& Ravenscroft, A. (2004). Addressing methodological issues in e-learning research. In Proceedings of the networked learning conference 2004. Retrieved 28 September 2011 from http://www.networkedlearningconference.org.uk/past/nlc2004/proceedings/sympo sia/symposium4/conole_et_al.htm

Creswell, J. W. (2009). Research design: Qualitative, quantitative and mixed methods approaches (3rd ed.). Thousand Oaks, CA: Sage.

de Villiers, M. R. (2005). Interpretive research models for informatics: Action research, grounded theory, and the family of design- and development research. Alternation, 12(2), 10-52.

Design-Based Research Collective. (2003). Design-based research: An emerging paradigm for educational inquiry. Educational Researcher, 32(1), 5-8.

Fallman, D. (2003). Design-oriented human-computer interaction. In G. Cockton \& P. Korhonen (Eds.), Proceedings of the conference on human factors in computing systems (pp. 225-232). New York: ACM Press.

Germonprez, M., \& Mathieassen, L. (2004). The role of conventional research methods in information systems action research. In B. Kaplan, D. P. Truex III, A. T. Wood-Harper, \& J. I. DeGross (Eds.), Information systems research-Relevant theory and informed practice (pp. 335-349). Kluwer Academic Publishers.

Glass, R. L., Ramesh, V., \& Vessey, I. (2004). An analysis of research in computing disciplines. Communications of ACM, 47(6), 89-94. doi:10.1145/990680.990686.

Hansson, H., Mozelius, P., Suhonen, J., Sutinen, E., Vesisenaho, M., \& Wettegren, G. (2009). ICT4D with a Nordic flavor-A stepwise and multithreaded approach. In P. Cunningham \& M. Cunningham (Eds.), IST-Africa 2009 conference proceedings. IIMC International Information Management Corporation.

Kerne, A. (2002). Concept-context-design: A creative model for the development of interactivity. In Proceedings of the fourth conference on creativity \& cognition (pp. 192-199). New York: ACM Press

Kommers, P. (2004). Concepts in the world of the mind. In P. A. M. Kommers (Ed.), Conceptual support systems for learning -Imaging the unknown (pp. 3-30). Amsterdam: IOS Press.

Laine, T. H., Myller, N., \& Suhonen, J. (2006). ViSCoS mobile: Learning computer science on the road. In A. Berglund \& M. Wiggberg (Eds.), Proceedings of Kolin Kolistelut-Koli calling,5th Finnish/Baltic sea conference on computer science education (pp. 16-19). Uppsala University.

Laine, T. H., \& Suhonen, J. (2008). Establishing a mobile blog system in a distance education environment. International Journal of Mobile Learning and Organisation, 2(2), 149-165.

Lowyck, J. (2002). Pedagogical design. In A. A. Adelsberger, B. Collins, \& J. M. Pawlowski (Eds.), Handbook on information technologies for education and training (pp. 199-218). Springer.

Meisalo, V., Sutinen, E., \& Torvinen, S. (2003). Choosing appropriate methods for evaluating and improving the learning process in distance programming courses. In Proceedings of 33rd ASEE/IEEE frontiers in education conference (FIE2003), Boulder, CO, USA.

Meisalo, V., Sutinen, E., \& Torvinen, S. (2004). Classification of exercises in a virtual programming course. In Proceedings of the 34th frontiers in education conference (FIE2004), Savannah, Georgia, USA.

Moonen, J. (2002). Design methodology. In A. A. Adelsberger, B. Collins, \& J. M. Pawlowski (Eds.), Handbook on information technologies for education and training (pp. 153-180). Springer.

Moreno, A., Myller, N., Sutinen, E., \& Ben-Ari, M. (2004). Visualizing programs with Jeliot 3. In Proceedings of the international working conference on advanced visual interfaces (pp. 373-376). New York: ACM Press. doi:10.1145/989863.989928.

Muller, M. J., \& Kuhn, S. (1993). Participatory design. Communications of the ACM, 36(6), 24-28.

Norman, D. A. (2002). The design of everyday things. New York: Basic Books.

Paliktzoglou, V., Rogers, C., \& Suhonen, J. (2010). Design challenges of developing an online PhD supervision community. In A. Psychogios, G. Eleftherakis, F. Proedrou, \& E. Kalyva (Eds.), Proceedings of the 5th annual South-East European doctoral student conference (pp. 401-411). Greece: Thessaloniki.

Quintana, C., Krajick, J., \& Soloway, E. (2002). A case study to distill structural scaffolding guidelines for scaffolded software environments. In Proceedings of the SIGCHI conference on human factors in computing systems: Changing our world, changing ourselves (pp. 81-88). New York: ACM Press.

Reeves, T. C. (2000a). Socially responsible educational technology research. Educational Technology, $40(6), 19-28$. 
Reeves, T. C. (2000b). Enhancing the worth of instructional technology research through "design experiments" and other development research strategies. Paper presented at international perspectives on instructional technology research for the 21st century symposium. Retrieved 28 September 2011 from http://it.coe.uga.edu/ treeves/AERA2000Reeves.pdf.

Simon, H. A. (1981). The sciences of the artificial (2nd ed.). Cambridge, MA: MIT Press.

Suhonen, J., \& Sutinen, E. (2004). Formative development method in action-Case of a digital learning tool. In Kinshuk, C.-K. Looi, E. Sutinen, D. G. Sampson, I. Aedo, L. Uden, \& E. Kähkönen (Eds.), Proceedings of the IEEE international conference on advanced learning technologies (pp. 720-722). Los Alamitos, CA: IEEE Computer Society.

Suhonen, J., \& Sutinen, E. (2006). FODEM: Developing digital learning environments in widely dispersed learning communities. Journal of Educational Technology \& Society, 9(3), 43-55.

Suhonen, J., \& Sutinen, E. (2007). Learning computer science over the Web: The ViSCoS odyssey. In R. C. Sharma \& S. Mishra (Eds.), Cases on global e-learning practices: successes and pitfalls (pp. 176-188). Idea Group Publishing.

Torvinen, S. (2004). Aspects of the evaluation and improvement process in an online programming courseCase: The ViSCoS program. Licenciate Thesis, Department of Computer Science, University of Joensuu, Finland.

Wang, F., \& Hannafin, M. J. (2005). Design-based research and technology-enhanced learning environments. Educational Technology Research and Development, 53(4), 5-23.

Zuber-Skerrit, O. (1992). Action research in higher education. London: Kogan Page.

Dr. Jarkko Suhonen holds a Senior Assistant position at the University of Eastern Finland, Finland. He has a $\mathrm{PhD}$ degree in Computer Acience. Dr. Suhonen has been involved in creating, managing and evaluating the ViSCoS (http://cs.joensuu.fi/viscos) distance learning program and he is currently the co-ordinator of the IMPDET (http://www.impdet.org) online PhD study program. In IMPDET doctoral program students study towards a PhD degree in computer science or in education specialising in educational technology. In his PhD thesis, Dr. Suhonen constructed and evaluated the FODEM method which was used to develop ViSCoS. He has co-authored and published over 40 academic papers.

M. Ruth de Villiers is a professor in the School of Computing at the University of South Africa (UNISA), South Africa, a distance-teaching institution, which emphasizes the role of research into open distance learning and educational technology. Prof. de Villiers has a $\mathrm{PhD}$ and also holds masters degrees in the domains of Information Systems and Computer-integrated Education, respectively. For more than 25 years, she has taught Computer Science and Informatics. Her major current research interests and teaching areas are Human-Computer Interaction and e-Learning. She has combined these areas by undertaking research and development in the usage, usability and usability evaluation of a broad variety of e-learning applications and other environments. She has also published in the focus area of meta-research, involving work on various research designs and methodologies.

Prof. Erkki Sutinen is the leader of the Technologies for Education and Development research group at University of Eastern Finland. His research interests include designing and analyzing technologies for complex subject domains, like programming, in developing countries, and within special education. Most of his externally funded research projects have involved diverse users as active designers of novel technical solutions. He has co-authored and published over 100 academic papers. 